\title{
Enhancement of Dimensional Stability of Rigid PVC Foams Using E-Glass Fibers
}

\author{
Murtatha M. Jamel, Parisa Khoshnoud, Subhashini Gunashekar, Nidal Abu-Zahra* \\ Materials Science and Engineering Department, University of Wisconsin-Milwaukee, Milwaukee, USA \\ Email: ${ }^{*}$ idal@uwm.edu
}

Received 7 February 2015; accepted 4 March 2015; published 5 March 2015

Copyright (C) 2015 by authors and Scientific Research Publishing Inc.

This work is licensed under the Creative Commons Attribution International License (CC BY).

http://creativecommons.org/licenses/by/4.0/

c) (†) Open Access

\section{Abstract}

Short cut E-glass fibers of two different lengths were used to determine the effect of glass fiber length on the dimensional stability of rigid Polyvinyl Chloride (PVC) foam in this study. Glass fibers measuring, 1/16" and 1/32" at different concentrations ( $0 \mathrm{wt} \%-20 \mathrm{wt} \%)$ were used to reinforce rigid PVC foams; the PVC foam-glass fiber (PVC-GF) composites were extruded using a single screw profile extruder. The extruded PVC-GF composites were characterized for their dimensional stability, structural, thermal, and mechanical properties. Experimental results show that the dimensional stability, heat resistance, and storage modulus were enhanced without compromising the tensile and flexural strengths of the composites. Thermal shrinkage decreased by almost $55 \%$ in composites reinforced with $1 / 32$ " GF and by $60 \%$ in composites reinforced with $1 / 16$ " GFs, with visible improvements to the shape distortion. Overall, foam composites which were prepared with longer (1/16") glass fibers exhibited better mechanical and thermal properties than those prepared with shorter (1/32") glass fibers. Microstructural observations suggest that this is due to better interlocking between the long fibers and the foam cells, which result in better load distribution in the matrix.

\section{Keywords}

Polyvinyl Chloride, PVC Foam, PVC Composites, Polymer Composites, Glass Fiber Composites, Reinforced Polymers

\section{Introduction}

Polymer foams are a unique class of materials that are widely used due to their light weight, low cost, and good formability along with load bearing and insulation capabilities. The cellular structure of the foam determines its

\footnotetext{
*Corresponding author.
}

How to cite this paper: Jamel, M.M., Khoshnoud, P., Gunashekar, S. and Abu-Zahra, N. (2015) Enhancement of Dimensional Stability of Rigid PVC Foams Using E-Glass Fibers. Journal of Minerals and Materials Characterization and Engineering, 3, 65-75. http://dx.doi.org/10.4236/jmmce.2015.32009 
mechanical and physical properties, and hence its performance and applications [1] [2]. Rigid Polyvinyl Chloride (PVC) foam and their composites have been used as an excellent replacement for wood in the building materials industry in the form of profiles, sheets, and pipes due to their low cost, low density, fire retardancy, and high insulation and damping properties. However, rigid PVC foams lack adequate dimensional stability when they are exposed to high and/or low temperatures. Certain applications of PVC foam products require excellent dimensional stability; such as in exterior moldings, siding, decking and railing applications. Solid fillers, such as calcium carbonate, talc, glass fibers (GF), carbon fibers, and wood fibers have been reported as effective PVC reinforcement additives in many publications [3]-[5]. The selection process of an effective reinforcement filler depends on its compatibility with the polymer matrix and the governing relationship between structure, property, and performance of the composite.

The use of GF as a reinforcement filler for improved dimensional stability in non-foam polymer composites has been studied and reported extensively. Raj et al. [6] studied the effect of heat exposure on the mechanical and thermal properties of glass fiber, mica and wood fiber reinforced low density polyethylene (LDPE); they reported that tensile strength and dimensional stability of the GF reinforced LDPE increased with increasing GF content. Canova et al. [7] studied GF (3.2 mm) and mica filled Polypropylene (PP) composites; they reported high dimensional stability and shrinkage reduction in GF-PP composites with higher filler contents. Jang et al. [8] prepared poly (butylene terephthalate) (PBT) filled GF composites using extrusion process. They reported enhancement in mechanical properties only when using sufficient coupling agents in order to improve the interfacial interaction between GF and the polymer matrix. They also claimed that the loading amount and length of GF, as well as the extrusion conditions determine the final mechanical properties of PBT-GF composites. Hassan et al. [9] prepared PP reinforced GF using maleic anhydride polypropylene (MAPP) as a coupling agent in extrusion and injection molding. They reported modest increase in the melting temperature of the composites with increasing GF and MAPP contents. Dynamic mechanical analysis (DMA) showed an improvement in the viscoelastic properties of the composite with low GF loadings in the presence of the coupling agent.

Although short GF are known to yield lower enhancement in their composites when compared to their longer counterparts, they are still widely used in polymer composites due to their processing advantages [10]. Ozkoc et al. [11] studied the effect of content and extrusion conditions of surface treated short GF on the mechanical properties of acrylonitrile-butadiene-styrene (ABS). In their work, polyamide-6 (PA6) was used at different levels to improve the interaction between GF and the matrix. They reported that the tensile strength, tensile modulus, flexural modulus, and impact strength of the composites are lower when using shorter glass fibers. However, mechanical properties improved slightly when using higher amounts of short GF and PA6. Thomason et al. [12] studied the effect of the length, diameter, and content of GF on the impact properties of polyamide 6, 6 reinforced with GF using notched and un-notched impact samples. They reported that the impact properties of the notched samples were more sensitive to the fiber length and content; while the fiber diameter and content were the main parameters affecting the impact strength of the un-notched samples. Jiang [13] studied the influence of short $(0.8 \mathrm{~mm})$ and long $(6.4 \mathrm{~mm}) \mathrm{GF}$ on the impact strength of PVC/wood flour/ GF at a constant loading level of 5\%. It was reported that the long GF improved the impact strength while maintaining flexural properties, whereas the short GF did not show any significant improvements. In addition, it has been reported elsewhere that glass fibers improve dimensional stability and mechanical strength in PVC composites [14] [15].

Deanin et al. [16] investigated the effect of adding GF on the dimensional stability of PBT foam composites. They reported enhancement in the dimensional stability when using coupling agents and surface treatments to enhance the interaction between the GF and polymer matrix. Similarly, Laurent et al. [17] studied the effect of surface treatment on the mechanical properties of foamed and un-foamed PVC reinforced with wood fibers. They observed a reduction in tensile modulus and tensile strength of the composites at higher GF loading, which was attributed to higher void fraction in the composites structure and weak interaction between the matrix and GF. Mengeloglu et al. [18] studied the mechanical properties of extruded foam PVC/wood-flour composites and reported similar results to Laurent et al. [17]. Tungjitpornkull et al. [19] prepared E-chopped GF filled wood/ PVC composites at different GF loadings, 10, 20 and $30 \mathrm{phr}$, with various fiber lengths 3, 6 and $12 \mathrm{~mm}$. They concluded that the most critical parameter in determining the tensile and flexural properties of the composites is the GF loading in the composite.

Based on our literature review, there is no published work on the effect of GF on the dimensional stability of PVC foams. In this study, the effect of GF content and length on the dimensional stability, as well as the mechanical, microstructural, and thermal properties of PVC foam composites, are investigated. 


\section{Experimental}

\subsection{Materials}

Rigid PVC resin was purchased from Shintech, USA; it had an inherent viscosity of 0.74 (ASTM D1243); bulk density of $36.3 \mathrm{lb} / \mathrm{ft}^{3}$ (ASTM D 1895), and maximum volatiles of $0.12 \%$ (ASTM D3030). A commercially available thermal stabilizer, Thermolite T-137, and processing aids, Plastistrength P530 and P770, were provided by Arkema, USA. Other ingredients used in preparing the samples are Lubricants Loxiol 2986 and 2987 produced by Oleochemicals; paraffin wax Petrac 215 produced by Ferro Corp.; Calcium Stearate COAD 10 produced by Norac Corp.; chemical blowing agents Azodicarbonamide (ADC) produced by Season Corp.; and Sodium Hydrogen Carbonate (FICEL SBH) produced by Hughes Polymer Additives Corporation. The specific content of each ingredient is considered proprietary; however the amount of each ingredient follows a common formulation used in making rigid PVC foams. Two types of milled and saline treated E-glass fibers, with lengths of 1/16" and 1/32" and diameter of 16 microns, were purchased from Fiber Glast Developments Corporation.

\subsection{Sample Preparation}

PVC foam compounds were prepared using a high shear mixer (Gunther Pepenmeier, Machinen-u. Detmoid, Type: TSHK). Initially, the PVC resin was added to the mixer at room temperature. Then, the stabilizer was added at $52^{\circ} \mathrm{C}$, glass fibers and processing aids were added at $58^{\circ} \mathrm{C}$. Finally, the lubricants and the blowing agents were added at $66^{\circ} \mathrm{C}$.

When the temperature reached $100^{\circ} \mathrm{C}$, the compound was collected from the mixer and allowed to cool down to room temperature before extrusion. The compounds were extruded using a 1.25 inch, 20:1 (L/D) single screw extruder (Thermoplast Extrusion Machine ${ }^{\circledR}$ from New England Wire Machinery Co.) at a screw speed of $60 \mathrm{rpm}$. The heating zones temperatures were in the range of $158^{\circ} \mathrm{C}$ to $175^{\circ} \mathrm{C}$. A rectangular profile die was used to extrude the samples. The extruded stream was air cooled prior to feeding through an aluminum sizer $(1 " \times 0.28$ ") placed in a vacuum chilled water tank. Finally, the extruded stream is cut into 12" pieces using an automated cutter. The composites formulations are listed in Table 1.

\subsection{Thermal Properties}

Thermal properties of the foam composites were analyzed using: 1) TA Instrument SDT 2960 thermo-gravimetric analysis equipment (TGA) in the temperature range of $25^{\circ} \mathrm{C}$ to $800^{\circ} \mathrm{C}$ at a heating rate of $10^{\circ} \mathrm{C} / \mathrm{min}$ under argon atmosphere; and 2) Differential Scanning Calorimetry (DSC) measurements using TA Q2000 analyzer (TA Instruments, US). Foam composite samples weighing 5 to $10 \mathrm{mg}$ were heated in standard aluminum pans in the temperature range of $25^{\circ} \mathrm{C}$ to $260^{\circ} \mathrm{C}$ at a heating rate of $10^{\circ} \mathrm{C} / \mathrm{min}$.

Dynamic Mechanical Analysis (DMA) was performed on TA Instrument Q800 to evaluate the viscoelastic properties (storage modulus, loss modulus, and $\tan \delta$ ) of composites in the solid state. A three-point bending mode was used at a test temperature range of $25^{\circ} \mathrm{C}$ to $120^{\circ} \mathrm{C}$ and a constant heating rate of $3^{\circ} \mathrm{C} / \mathrm{min}$ at $1 \mathrm{~Hz}$ frequency of dynamic force.

Table 1. PVC foam composites formulation.

\begin{tabular}{|c|c|c|c|c|c|c|c|}
\hline \multirow{2}{*}{$\begin{array}{l}\text { Sample } \\
\text { Number }\end{array}$} & \multicolumn{2}{|c|}{ Glass Fiber } & PVC Resin & Stabilizer & Blowing Agents & Lubricants & Processing Aid \\
\hline & \multicolumn{7}{|c|}{ Content (wt\%) } \\
\hline GF0 & \multicolumn{2}{|c|}{0} & 92.5 & \multirow{9}{*}{0.85} & \multirow{9}{*}{0.5} & \multirow{9}{*}{0.6} & \multirow{9}{*}{6} \\
\hline GF5 & \multirow{4}{*}{$1 / 16^{\prime \prime}$} & 5 & 87.5 & & & & \\
\hline GF10 & & 10 & 82.5 & & & & \\
\hline GF15 & & 15 & 77.5 & & & & \\
\hline GF20 & & 20 & 72.5 & & & & \\
\hline GF5 & \multirow{4}{*}{$1 / 32^{\prime \prime}$} & 5 & 87.5 & & & & \\
\hline GF10 & & 10 & 82.5 & & & & \\
\hline GF15 & & 15 & 77.5 & & & & \\
\hline GF20 & & 20 & 72.5 & & & & \\
\hline
\end{tabular}


The dimensional stability of the foam composites was analyzed using AAMA (American Architectural Manufacturers Association) standards. Extruded samples were heated in an oven at $82^{\circ} \mathrm{C}$ for 30 minutes. The original dimensions of the foam composites were $12 " \times 1 " \times 0.28$ ". The change in length was measured after 4 hours and reported as a shrinkage percentage according to Equation (1), where $l_{o}$ and $l_{f}$ are the initial and final lengths; respectively:

$$
\% \text { Shrinkage }=\frac{l_{0}-l_{f}}{l_{0}} \times 100
$$

Heat resistance of the composites were analyzed according to AAMA standards. Extruded samples were heated in an oven at $141^{\circ} \mathrm{C}$ for 30 minutes. The original dimensions of the foam composites were $12^{\prime \prime} \times 1 " \times$ 0.28". Visual inspection on the samples was done to determine the presence of any flaws or distortion after cooling down for four hours on a dry and clean surfaces.

\subsection{Mechanical Properties}

Tensile properties were determined using an Instron 3365 universal testing machine on rectangular specimens measuring $12 " \times 1 " \times 0.28 "$ at a crosshead speed of $0.5 \mathrm{in} / \mathrm{min}$. Flexural properties were determined using Instron 3365 with a three-point bending test set-up on rectangular specimens measuring 8 " $\times 1$ " $\times 0.28$ " at a crosshead speed of $0.5 \mathrm{in} / \mathrm{min}$. The span length was kept at 4 inches. The flexural stress and strains were calculated using Equations (2) and (3):

$$
\begin{gathered}
\sigma_{f}=\frac{3 P L}{2 b d^{2}} \\
\varepsilon_{f}=\frac{6 D d}{L^{2}}
\end{gathered}
$$

where, $\sigma_{f}$ and $\varepsilon_{f}$ are the respective flexural stress and strain at the midpoint, and $P, L, b, d, D$ are the load, span length, specimen width, specimen thickness and midpoint deflection; respectively. The flexural strength was determined using the maximum stress value recorded before sample fracture and flexural modulus was determined by the slope of the initial linear region of the stress-strain curve.

Charpy impact properties were determined using Tinus Olsen impact testing machine (model IT 504) according to ASTM D 6110. Four samples of each composite were tested. The dimensions of the impact testing samples were $5 " \times 0.5^{\prime \prime} \times 0.28$ " with a $45^{\circ}$ notch at the middle.

\subsection{Scanning Electron Microscopy (SEM)}

Topcon SM-300 SEM was used for imaging and microstructural analysis of the extruded PVC-GF foam composites. The specimens were fractured in liquid nitrogen and coated using a sputter coater to minimize the charging effect and to improve the conductivity of the samples prior to analysis.

\section{Results and Discussion}

\subsection{Microstructure and Morphology}

The dispersion and surface bonding of the solid phase with the host polymer matrix affects many important characteristics; such as mechanical properties and dimensional stability [16] [17]. Therefore, it is important to study the fiber-matrix interface in order to explain the characteristics and behavior of these composites. Figures 1(a)-(d) shows the dispersion of 1/16" GFs in the PVC foam matrix at 50x magnification; whereas Figures 2(a)-(d) shows the dispersion of 1/32" GFs in the PVC foam matrix at 150x magnification. One can observe in both sets of micrographs the random orientation and dispersion of GF in the matrix, and the penetration of the long fibers through the closed cell walls. In the case of 1/16" GFs, the penetration is across multiple cell walls, as shown in Figure 1(c); whereas the penetration in the case of 1/32" GFs is mostly limited to individual cell walls, as shown in Figure 2(c). Fiber dispersion is a function of the fiber lengths; shorter fibers tend to agglomerate more than the longer fibers during processing due to the liquid additives used in the compounding process. 

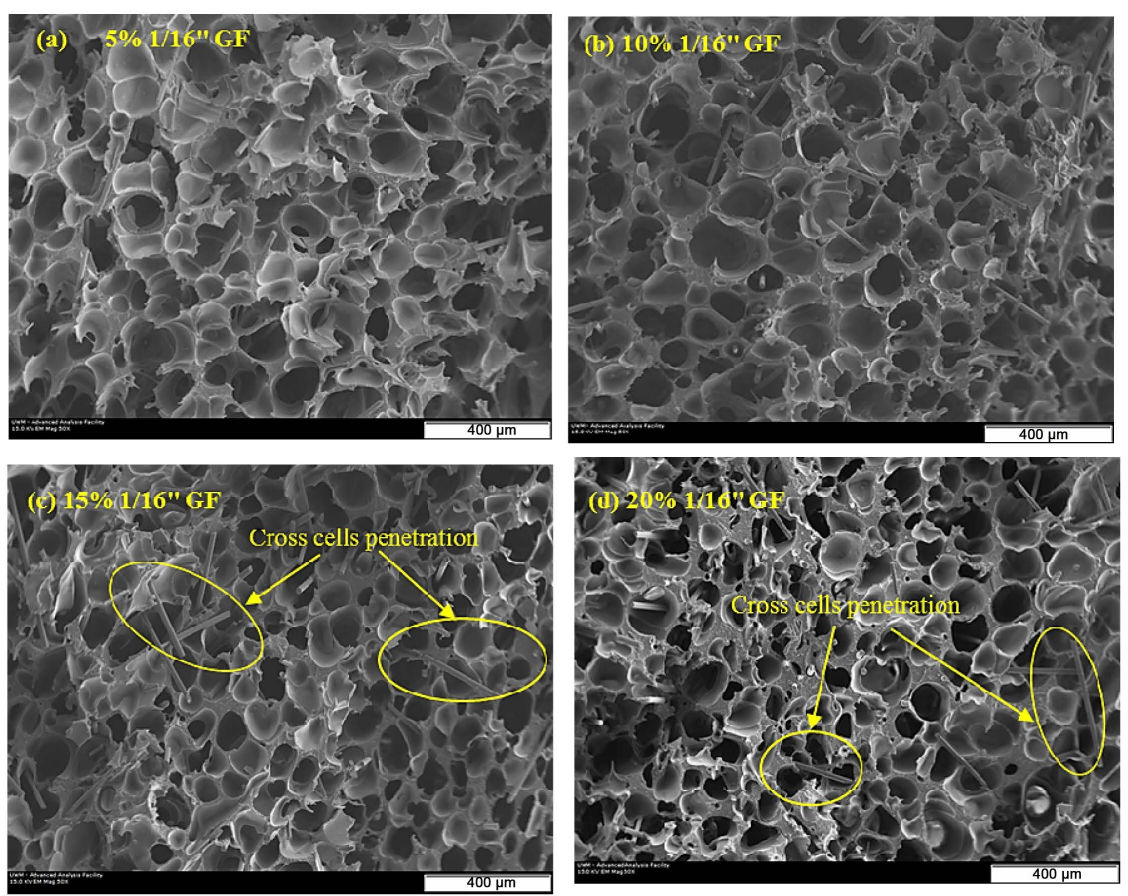

Figure 1. SEM micrographs at 50× of 1/16" GF-PVC (a) 5\% (b) $10 \%$ (c) $15 \%$ (d) $20 \%$.
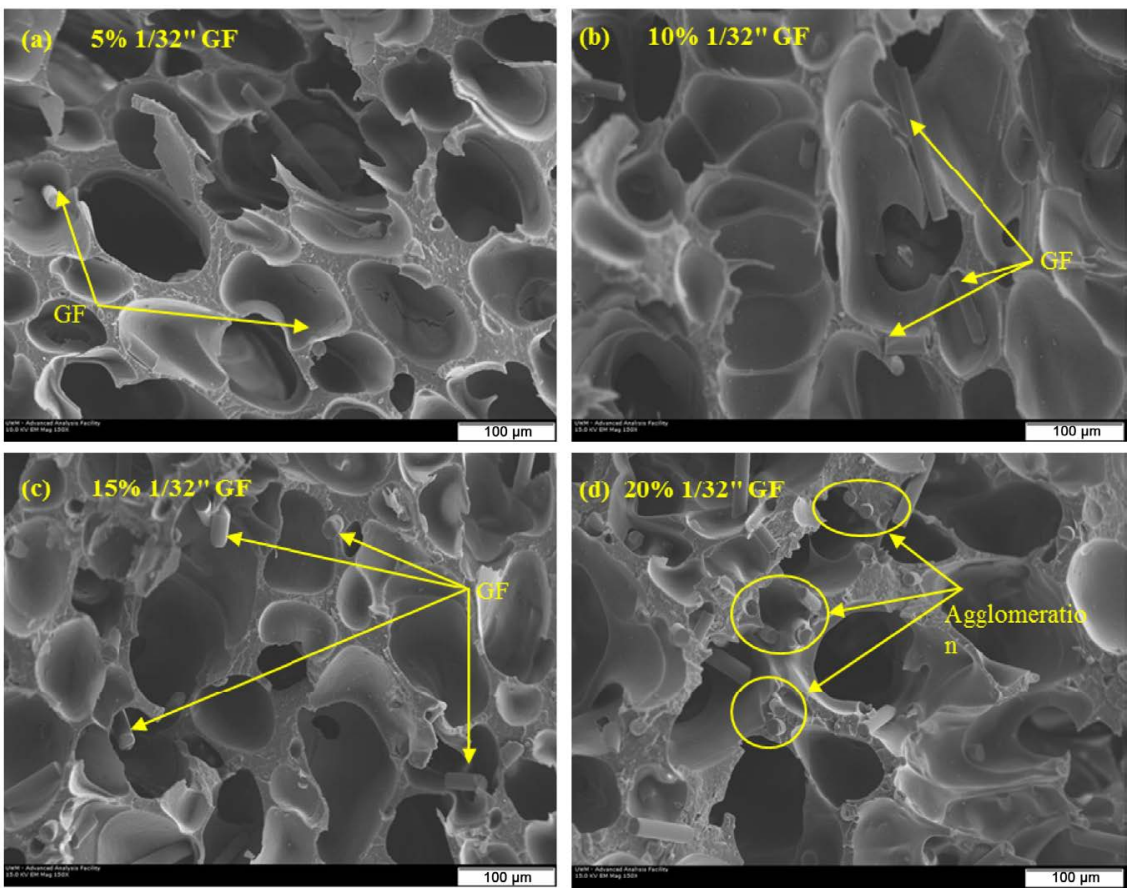

Figure 2. SEM micrographs at $150 \times$ of 1/32" GF-PVC (a) 5\%; (b) 10\%; (c) 15\%; (d) $20 \%$.

Figure 3 shows a close up image of a fiber-matrix interface at $1000 \times$ magnification. The orientation of this particular fiber is along the fracture surface, whereas the majority of fibers which are present in the foam matrix are across the fracture surfaces. However, the fracture surface shown in Figure 3 seems to be clean, which indicates poor bonding between the two surfaces. In addition, the diameter of the GF seems to be close to the thickness of the cell wall, or higher at some locations. Both these observations may be significant to the effect of GF on the mechanical and thermal performance of the composite matrix. 


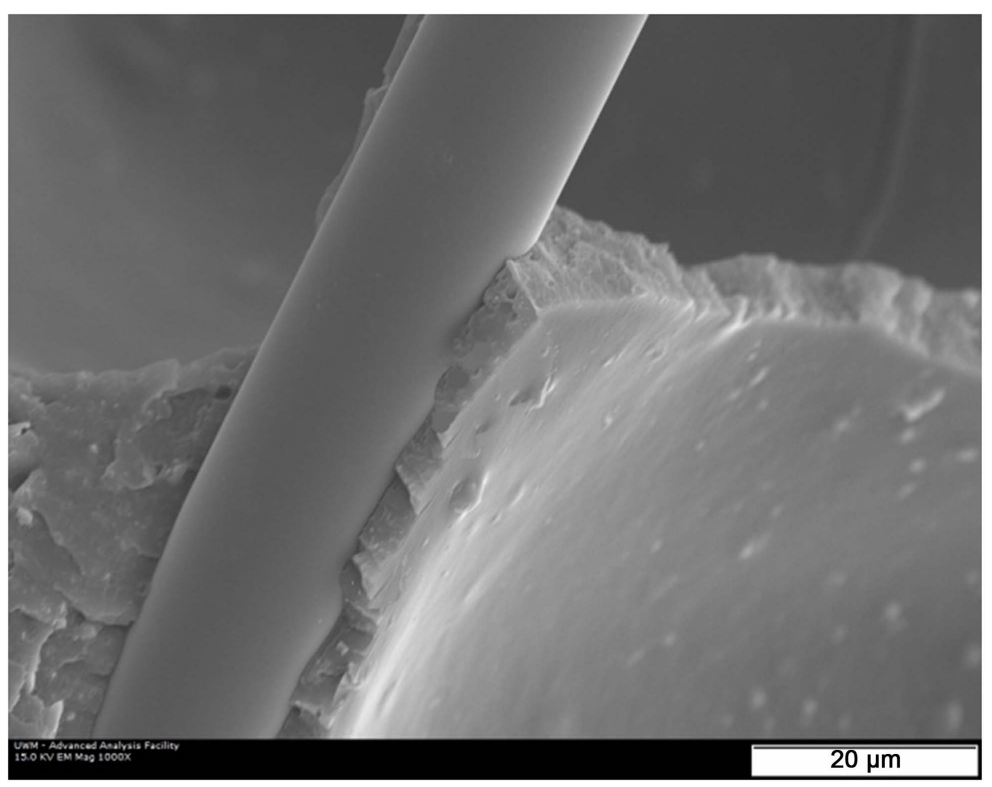

Figure 3. SEM micrograph at $1000 \times$ of a glass fiber interface with PVC foam.

\subsection{Thermal Properties}

Dimensional stability of the foam composites was measured as a percentage of shrinkage; the effect of GF lengths and loading is presented in Figure 4 . The percentage of shrinkage decreased by $22.5 \%$ and $28.4 \%$ when adding $5 \%$ of $1 / 32$ "and 1/16" GFs; respectively, compared with pristine samples. It is evident that dimensional stability increases significantly with increasing the GF content in the composites. This is due to the higher solid content in the polymer matrix, which has higher resistance to thermal expansion and/or contraction. A comparison between the samples made with the same filler content at different GF lengths reveals that the composites containing longer GF (1/16") exhibit higher dimensional stability improvement than those with shorter GF. This may be attributed to a higher interlocking and bonding between longer GF and the foam matrix along the fiber length. Since GF has lower coefficient of thermal expansion than the polymer matrix, higher interaction between the fibers and the matrix improves dimensional stability of the composites.

Heat resistance was evaluated qualitatively by visual inspection for surface flaws and shape distortion of the extruded samples after subjection to heating and cooling cyles. Although, the test samples did not show any flakes or cracks on the surface, some distortion was observed on the sides. It was also observed that the addition of GF reduced the amount of swelling. In addition, the composites containing 1/16" GFs exhibited higher heat resistance when compared with those containing shorter GF lengths. Meanwhile, the addition of GF does not seem to affect the glass transition temperature (Tg) of the PVC foam composites, around $82^{\circ} \mathrm{C}$, as shown in Table 2. Similar conclusions were presented by Hassan et al. [9].

The results from TGA analysis of PVC-GF foam composites are presented in Figure 5. The average Primary Degradation Temperature (PDT) of the foam composites begins around $277^{\circ} \mathrm{C}$, while the average Secondary Degradation Temperature (SDT) is around $440^{\circ} \mathrm{C}$.

Increasing GF content increases the secondary decomposition temperature of the composites, as shown in Table 3, which means that it takes more energy to break the hydrocarbon backbone of the polymer matrix [20] [21]. On the other hand, the PDT of the composites, which indicates the start of the separation process of chlorine from the polymer chains, decreases slightly by increasing the GF content. This can be attributed to the higher thermal conductivity of GF, which results in faster heat transfer into the PVC matrix and thermal degradation starting at lower temperatures [21]. The residual weight at $800^{\circ} \mathrm{C}$ is found to increase with increasing GF content due to the higher content of inorganic filler in the matrix.

Thermo mechanical properties of the PVC-GF composites were determined by DMA analysis. Variations in the storage modulus (E'), which represents the elastic behavior, and the loss modulus (E"), which represents the viscous behavior, with temperature, are shown in Figure 6 and Figure 7; respectively. The storage modulus and the peak intensity of the loss modulus increased with the addition of GFs and were the highest at $15 \%$ GF, for both 


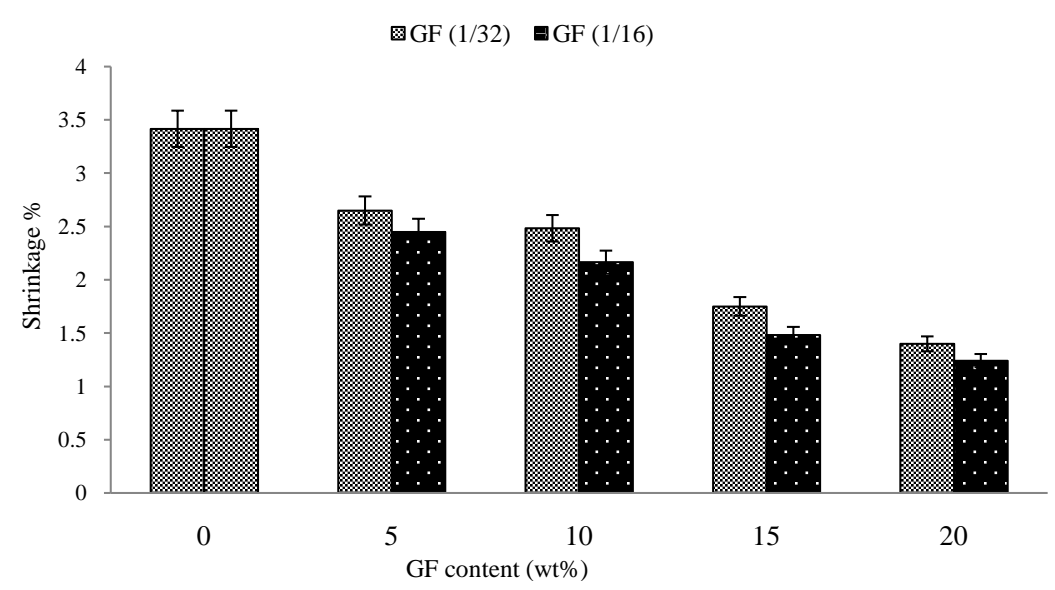

Figure 4. Dimensional stability of PVC-GF foam composites.

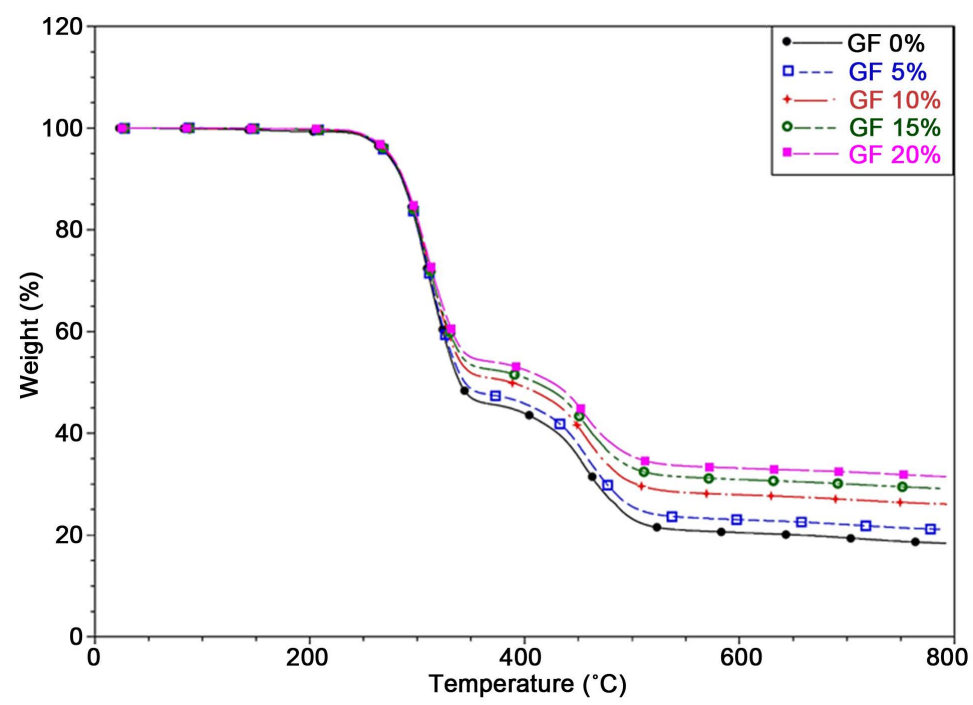

(a)

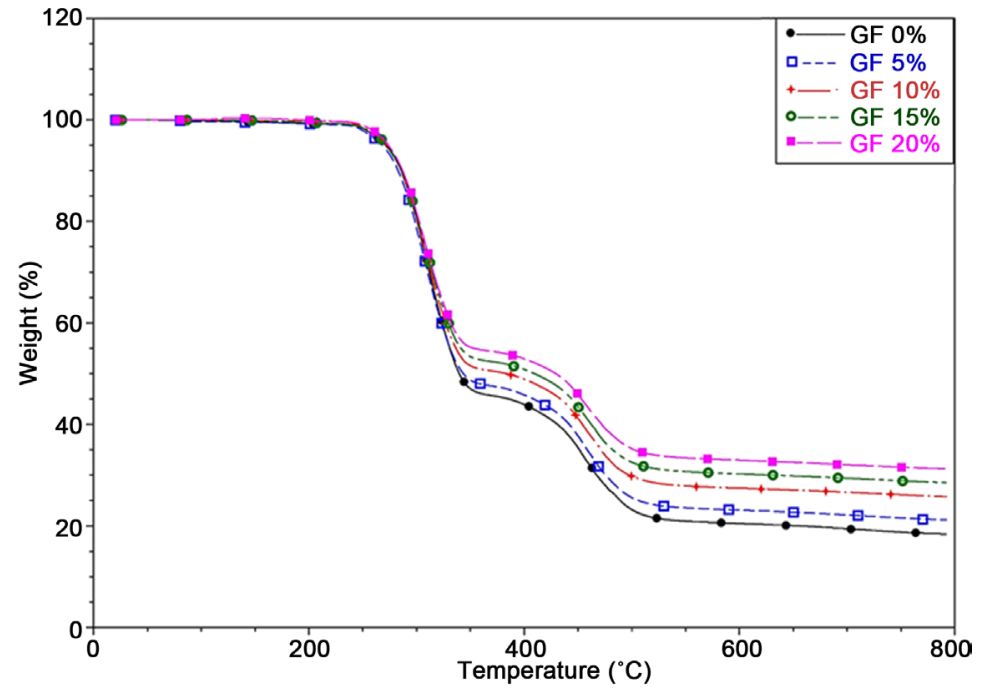

(b)

Figure 5. TGA analysis for PVC-GF composites (a) 1/16"; (b) 1/32". 


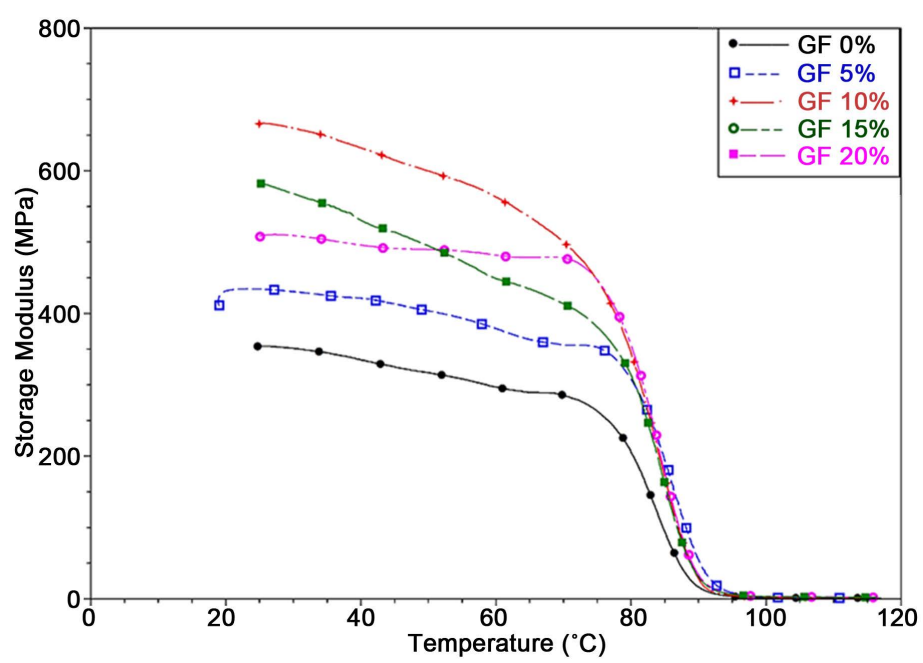

(a)

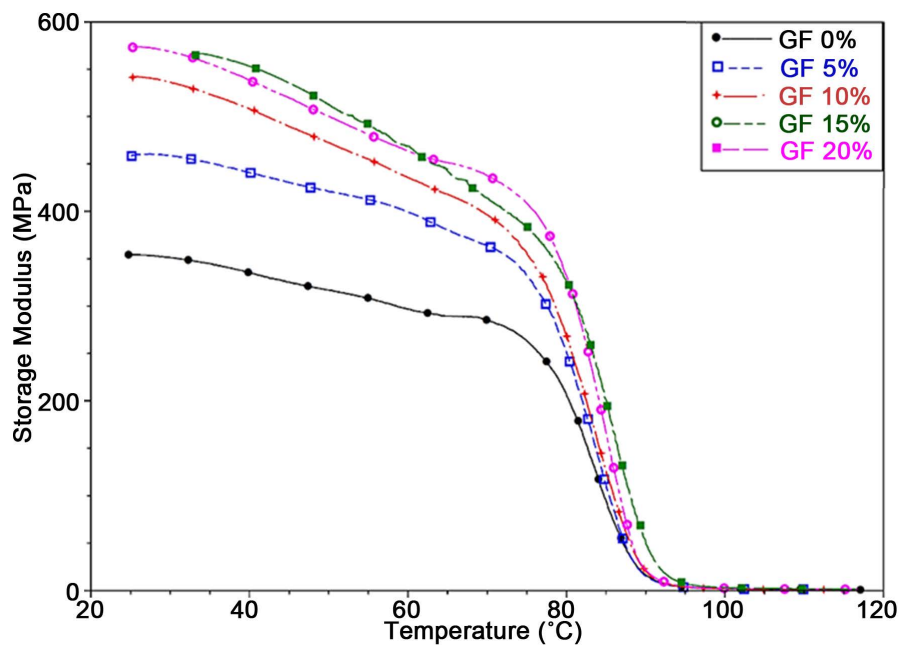

(b)

Figure 6. Storage Modulus (E') of PVC-GF composites (a) 1/16"; (b) 1/32". The curves are labeled with respect to the value of storage modulus from top to bottom.

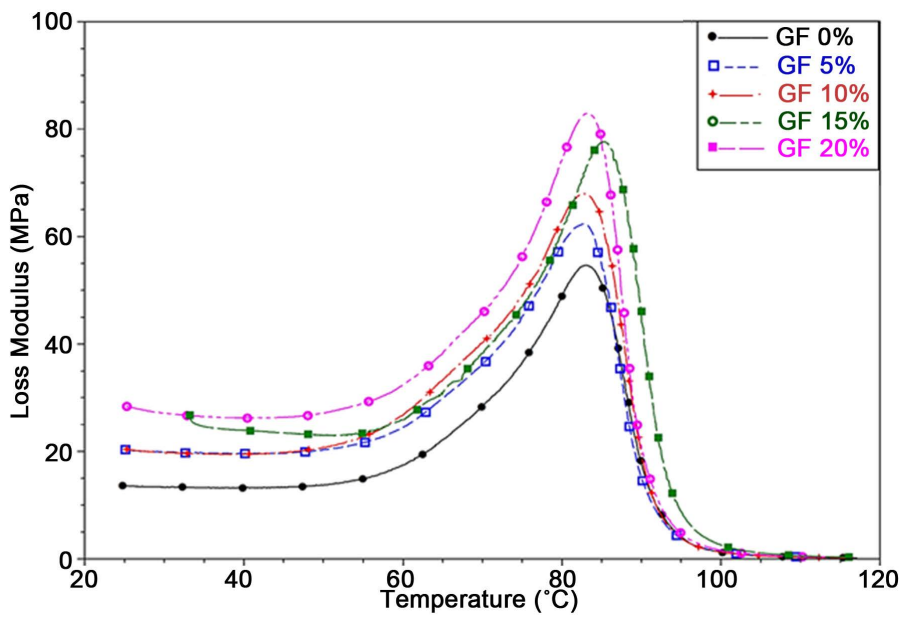

(a) 


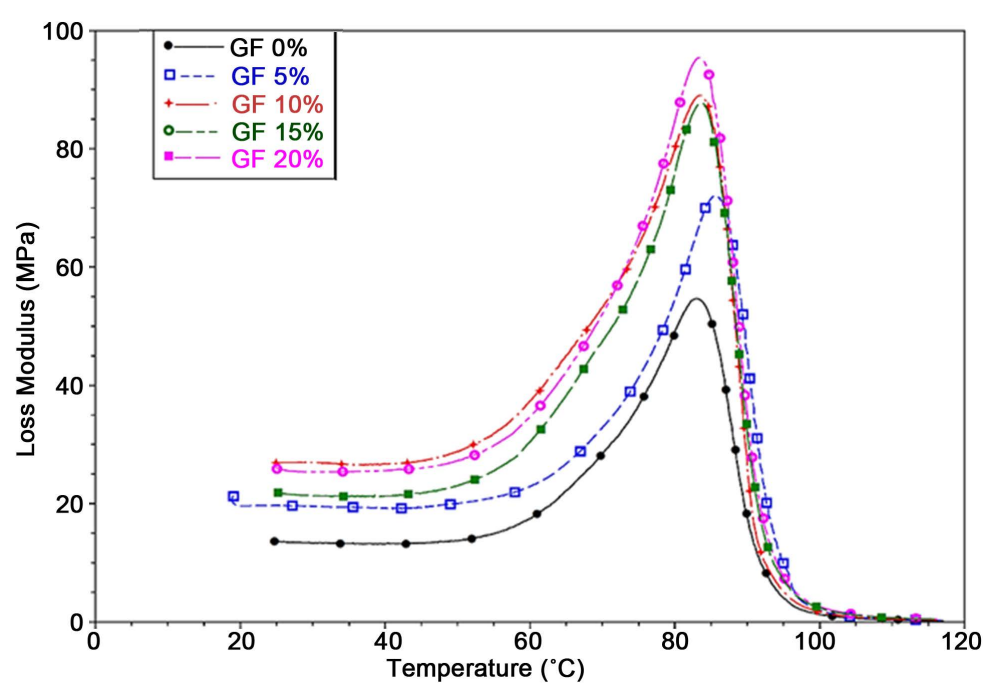

(b)

Figure 7. Loss Modulus (E") of PVC-GF composites (a) 1/16"; (b) 1/32". The curves are labeled with respect to the value of loss modulus from top to bottom.

Table 2. Glass transition temperatures of the GF-PVC composites measured by DSC.

\begin{tabular}{cccccccccc}
\hline GF wt $\%$ & $\mathbf{0} \%$ & \multicolumn{2}{c}{$\mathbf{5 \%}$} & \multicolumn{2}{c}{$\mathbf{1 0 \%}$} & \multicolumn{2}{c}{$\mathbf{1 5 \%}$} & \multicolumn{2}{c}{$\mathbf{2 0 \%}$} \\
\hline Fiber Length & N/A & $1 / 16^{\prime \prime}$ & $1 / 32 "$ & $1 / 16 "$ & $1 / 32 "$ & $1 / 16 "$ & $1 / 32 "$ & $1 / 16^{\prime \prime}$ & $1 / 32 "$ \\
Tg $\left({ }^{\circ} \mathbf{C}\right)$ & 82.21 & 82.47 & 81.93 & 82.97 & 83.8 & 81.89 & 83.12 & 81.56 & 82.3 \\
\hline
\end{tabular}

Table 3. Primary and secondary decomposition temperature of PVC-GF composites.

\begin{tabular}{crrcc}
\hline Sample & \multicolumn{2}{c}{ Glass Fiber } & PDT $\left({ }^{\circ} \mathbf{C}\right)$ & SDT $\left({ }^{\circ} \mathbf{C}\right)$ \\
\hline GF0 & & & 279.39 & 442.25 \\
GF5 & & $5 \%$ & 278.21 & 439.36 \\
GF10 & $10 \%$ & 278.57 & 441.78 \\
GF15 & $1 / 16 "$ & $15 \%$ & 276.73 & 440.63 \\
GF20 & & $20 \%$ & 277.31 & 439.04 \\
GF5 & & $5 \%$ & 276.66 & 436.23 \\
GF10 & $10 \%$ & 277.15 & 437.73 \\
GF15 & $1 / 32 "$ & 277.23 & 437.85 \\
GF20 & & $20 \%$ & 277.27 & 443.67 \\
\hline
\end{tabular}

GF lengths. This is attributed to the enhancement in the energy dissipation ability in the presence of solid fillers in the polymer matrix and the increase in the polymer-filler and filler-filler slippages at Tg [21] [22].

However, at 20 wt\% GF concentration, the magnitude of E' and E" decrease due to the agglomeration of GFs at higher concentrations, as was shown earlier by SEM analysis (Figure 2(d)). The agglomeration of GFs leads to higher friction between the fibers and less interaction between the reinforcing phase and the host matrix. Consequently, the energy dissipation in the reinforced polymer matrix is reduced [17]. Similarly, the composites with 1/16" GFs exhibit higher storage and loss moduli compared to the $1 / 32$ " GFs. The storage modulus increased from $350 \mathrm{MPa}$ to $650 \mathrm{MPa}$ with the addition of 10\% 1/16" GFs; whereas it increased only to $550 \mathrm{MPa}$ with the addition of 10\% 1/32" GFs. The loss modulus (E") peak increased to from $53 \mathrm{MPa}$ to $95 \mathrm{MPa}$ and 83 MPa in the case of 15\%-1/16" and 15\%-1/32" GFs; respectively. This is also attributed to the higher energy dissi- 
pation in the presence of longer glass fibers due to higher interaction between the fibers and the polymer matrix.

\subsection{Mechanical Properties}

The mechanical properties of polymer GF composites highly depend on the geometry of the reinforcement phase; such as the length and diameter of the GF [12]. Table 4 summarizes the effect of GF length and content on the mechanical properties of PVC-GF composites. Since the bonding between GFs and the polymer foam occurs only through the cell walls, the enhancement in the foam strength is limited and is greatly affected by the bonding strength between the two surfaces. However, longer fibers are likely to have more bonding sites due to higher penetration through the walls of the closed cell foams. The ultimate tensile strength (UTS) of the composite foams seems to maintain its value at different loadings of GF. Meanwhile, the composites made with longer glass fibers $(1 / 16 ")$ seem to have slightly higher UTS at all loading levels. A similar effect of the glass fibers length on the UTS is also visible with the flexural strength measurements shown in Table 4.

The ductility of the PVC-GF composites, measured by the extension at break, was noticed to decrease in the presence of glass fibers. Higher amounts of GFs in the polymer matrix render the composite more brittle and prone to brittle fracture as they are dispersed in the matrix with no specific orientation. Longer GF (1/16") exhibit higher reduction in ductility compared to the shorter fibers; this is also attributed to the higher penetration of the longer fibers in the walls of the closed cell foams which increases the stiffness of the structure.

The impact strength of the PVC-GF composites decreases with the addition of GFs irrespective of their lengths. In the case of $1 / 16 "$ GFs, the impact strength decreased from $33 \mathrm{~J} / \mathrm{m}^{2}$ at $5 \% \mathrm{GF}$ to $25 \mathrm{~J} / \mathrm{m}^{2}$ at $20 \% \mathrm{GF}$, which is a $24 \%$ reduction. However, the reduction in impact strength in the case of $1 / 32$ " GFs was higher and at $29 \%$, i.e., $31 \mathrm{~J} / \mathrm{m}^{2}$ at $5 \% \mathrm{GF}$ and $22 \mathrm{~J} / \mathrm{m}^{2}$ at $20 \% \mathrm{GF}$. The longer fibers tend to strengthen the composite matrix as they are able to penetrate across multiple cell walls and thus interlocking the matrix between the fibers themselves, which leads to better load distribution [13].

\section{Conclusions}

Dimensional stability of PVC-GF foam composites measured by thermal shrinkage and heat resistance was improved significantly with the addition of GF to the foam composites. Thermal shrinkage decreased by almost $60 \%$, with visible improvements to the shape distortion. Longer GF yielded better improvement than shorter fibers due to their higher interaction with the foam cells. SEM images of the foam cells confirmed the random distribution and orientation of the GF in the polymer matrix; the connections between the GFs and the matrix are only through the walls of the foam-matrix. Also, SEM images confirmed that longer GFs exhibit higher crossings through the composite walls, and more interlocking between the fibers themselves.

Mechanical properties of the PVC-GF composites have mixed reactions. Whereas the tensile and flexural strengths seem to be marginally affected by the addition of GFs, the ductility and impact strengths decreased significantly with higher GF loadings. However, longer GFs scored better than their shorter counterparts due to

Table 4. Mechanical properties of PVC-GF composites.

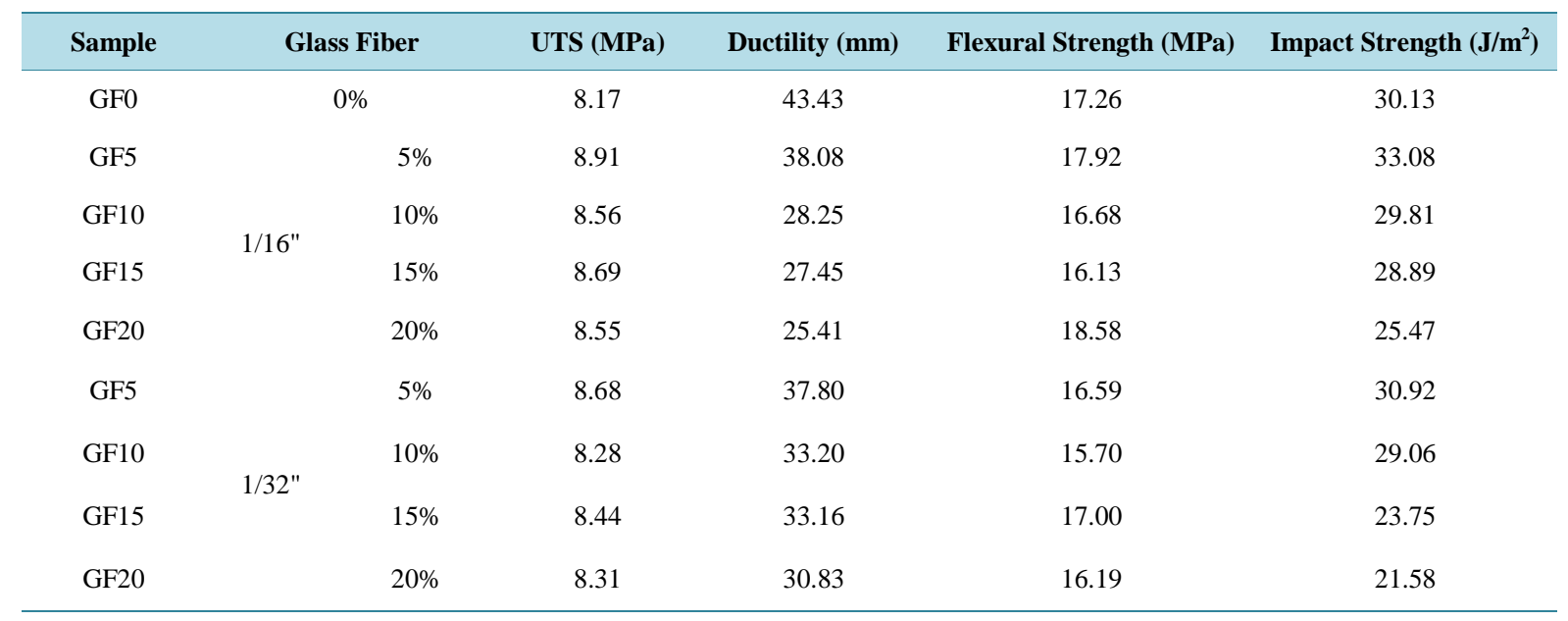


higher interlocking between the fibers and the foam cells, which results in better load distribution in the matrix. The viscoelastic properties of the PVC-GF composites measured by storage and loss moduli were enhanced by the addition of GFs with better improvements in the case of longer GFs.

\section{References}

[1] Shen, L., Haufe, J. and Patel, M. (2009) Product Overview and Market Projection of Emerging Bio-Based Plastics. Utrecht University, Netherlands.

[2] Lee, S., Park, C. and Ramesh, N. (2007) Polymeric Foams. Boca Raton, 8-21.

[3] British Plastic and Rubber (2003) Mineral Fillers for PVC Reinforcement. http://www.highbeam.com/doc/1G1-111617437.html

[4] Jiang, H. and Kamdem, D.P. (2004) Development of Poly(vinyl chloride)/Wood Composites. A Literature Review. Journal of Vinyl and Additive Technology, 10, 59-69. http://dx.doi.org/10.1002/vnl.20009

[5] Ráthy, I., Kuki, Á., Borda, J., Deák, G., Zsuga, M., Marossy, K. and Kéki, S. (2012) Preparation and Characterization of Poly(vinyl chloride)-Continuous Carbon Fiber Composites. The Journal of Applied Polymer Science, 124, 190-194. http://dx.doi.org/10.1002/app.33617

[6] Raj, R.G., Kokta, B.V. and Daneault, C. (1990) A Comparative Study on the Effect of Aging on Mechanical Properties of LLDPE-Glass Fiber, Mica, and Wood Fiber Composites. The Journal of Applied Polymer Science, 40, 645-655. http://dx.doi.org/10.1002/app.1990.070400502

[7] Canova, L.A., Ferguson, L.W., Parrinello, L.M. and Subramanian, R. (1997) Effect of Combinations of Fiber Glass and Mica on the Physical Properties and Dimensional Stability of Injection Molded Polypropylene Composites. Proceedings of 55th Annual Technical Conference Society of Plastics Engineering, Vol. 2, 2112-2116.

[8] Jang, S.H., Kim, Y.H., Lim, S., Choi, G.D., Kim, S.H. and Kim, W.N. (2010) Effects of Fiber Characteristics on the Mechanical and Rheological Properties of Poly(butylene terephthalate)/Glass Fiber Composites. The Journal of Applied Polymer Science, 116, 3005-3012.

[9] Hassan, A., Rahman, N. and Rosiyah, Y. (2011) Extrusion and Injection-Molding of Glass Fiber/MAPP/Polypropylene: Effect of Coupling Agent on DSC, DMA, and Mechanical Properties. Journal of Reinforced Plastics and Composites, 30, 1223-1232.

[10] Young, R. and Lovell, P. (2011) Introduction to Polymers. 3rd Edition, Boca Raton, 613-614.

[11] Ozkoc, G., Bayram, G. and Bayramli, E. (2005) Short Glass Fiber Reinforced ABS and ABS/PA6 Composites: Processing and Characterization. Polymer Composites, 26, 745-755. http://dx.doi.org/10.1002/pc.20144

[12] Thomason, J. (2009) The Influence of Fibre Length, Diameter and Concentration on the Impact Performance of Long Glass-Fiber Reinforced Polyamide 6,6. Composites Part A: Applied Science and Manufacturing, 40, 114-124.

[13] Jiang, H., Pascal Kamdem, D., Bezubic, B. and Ruede, P. (2003) Mechanical Properties of Poly(Vinyl Chloride)/Wood Flour/Glass Fiber Hybrid Composites. Journal of Vinyl and Additive Technology, 9, 138-145. http://dx.doi.org/10.1002/vnl.10075

[14] Katz, H. and Mileski, H. (1987) Handbook of Fillers for Plastics. New York, 132-152.

[15] White, L.J. (1990) Principles of Polymer Engineering Rheology. USA.

[16] Rudolph, D. and Deanin, G.R. (1983) Glass-Fiber-Reinforced Poly(Butylene Terephthalate) Structural Foam. In: ANTEC 83: Plastics Engineering Today for Tomorrow's World, Chicago, 2-5 May1983, 277-279.

[17] Matuana, L.M., Park, C.B. and Balatinecz, J.J. (1998) Cell Morphology and Property Relationships of Microcellular Foamed PVC/Wood-Fiber Composites. Polymer Engineering \& Science, 38, 1862-1872. http://dx.doi.org/10.1002/pen.10356

[18] Mengeloglu, F. and Matuana, L.M. (2003) Mechanical Properties of Extrusion-Foamed Rigid PVC/Wood-Flour Composites. Journal of Vinyl and Additive Technology, 9, 26-31. http://dx.doi.org/10.1002/vnl.10058

[19] Tungjitpornkull, N., Chaochanchaikul, K. and Sombatsompop, N. (2007) Mechanical Characterization of E-Chopped Strand Glass Fiber Reinforced Wood/PVC Composites. Journal of Thermoplastic Composite Materials, 20, 535-550.

[20] Qiao, J., Amirkhizi, A., Schaaf, K. and Nemat-Nasser, S. (2010) Dynamic Mechanical Analysis of Fly Ash Filled Polyurea Elastomer. Journal of Engineering Materials and Technology, 133, Article ID: 011016.

[21] Khoshnoud, P., Gunashekar, S., Jamel, M.M. and Abu-Zahra, N. (2014) Comparative Analysis of Rigid PVC Foam Reinforced with Class C and Class F Fly Ash. Journal of Minerals and Materials Characterization and Engineering, 2, 554-565. http://dx.doi.org/10.4236/jmmce.2014.26057

[22] Luong, D., Pinisetty, D. and Gupta, N. (2013) Compressive Properties of Closed-Cell Polyvinyl Chloride Foams at Low and High Strain Rates: Experimental Investigation and Critical Review of State of the Art. Composites Part B: Engineering, 44, 403-416. http://dx.doi.org/10.1016/j.compositesb.2012.04.060 